\title{
SPECTROSCOPIC INVESTIGATIONS OF GALACTIC OPEN CLUSTER COLLINDER 394 - NEW RESULTS
}

\author{
I. A. Usenko ${ }^{1}$, A. Yu. Kniazev ${ }^{3,4}$, A.S. Miroshnichenko, ${ }^{5,6,7}$, S. Danford ${ }^{5}$, V. V. Kovtyukh ${ }^{2}$, \\ T. V. Mishenina ${ }^{2}$ \\ ${ }^{1}$ Mykolaiv Astronomical Observatory, Obsevatorna 1, Mykolaiv 54030, Ukraine, \\ igus99@ukr.net \\ 2 Astronomical Observatory, Odessa National University, Shevchenko Park, \\ Odessa 65014, Ukraine,vkovtyukh@ukr.net \\ 3 South African Astronomical Observatory, P.O. 7925, Cape Town, \\ South Africa, akniazev@saao.ac.za \\ ${ }^{4}$ Southern African Large Telescope Foundation, P.O. 7925, Cape Town, \\ South Africa \\ ${ }^{5}$ Dept. of Physics and Astronomy, University of North Carolina at \\ Greensboro, P.O.Box 261170, Greensboro, NC 27402, USA, a_mirosh@uncg.edu \\ ${ }^{6}$ Main Astronomical Observatory of the Russian Academy of Sciences, \\ Pulkovskoe shosse 65-1, Saint-Petersburg, 196140, Russia \\ 7 Fesenkov Astrophysical Institute, Observatory 23, Almaty, 50020, Kazakhstan
}

\begin{abstract}
Confident main-sequence (MS) members of the Collinder 394 open cluster are perfect objects to check the correctness of their distances, obtained from the GAIA GR2 (2018) catalogue. The differences in the distances to the open cluster Collinder 394, determined by photometry and from the GAIA parallaxes have raised doubts about the correctness of the latter. Therefore we used spectroscopically determined $T_{\text {eff }}$ and log gvalues for these stars from Usenko et al. (2019) and tried to solve the inverse problem: determine radii of these stars using the derived distances and calibrations " $T_{\text {eff- }}$ radius" for MS stars and compare with similar ones. For this purpose we used the calibrations from Torres et al. (2010), based on the nearest MS eclipsing binaries and compilations for MS stars from Mamajek (2018). As a result, we obtained relationships that connect $T_{\text {eff }}, \log \mathrm{g}$, radii, masses, and distances for the confident Collinder 394 MS stars. We have confirmed the correctness of the GAIA DR2 (2018) distances for these stars and determined their radii and masses. The latter estimates turned out to be close to those of the evolutionary masses calculated by the PARSEC models.
\end{abstract}

АНОТАЦІЯ. Справжні члени головної послідовності (ГП) розсіянного скупчення Collinder 394 є досконалі об'єкти для перевірки дійсності їх відстаней, отриманих 3 каталога GAIA GR2 (2018). Відмінності відстаней до розсіяного скупчення Collinder 394, що визначені фотометрією та 3 паралаксів GAIA, викликали сумніви щодо правильності останнього. Тому ми використовували спектроскопічно визначені значення $T_{\text {effi }} \log$ ддля цих зірок від Usenko et al. (2019) і спробував вирішити зворотню задачу: визначити радіуси цих зірок, використовуючи отримані відстані та калібрування " $T_{\text {eff- }}$ радіус" для зірок ГП, та порівняти 3 подібними. Для цього ми використовували калібрування від Torres et al. (2010), на основі найближчих подвійних затемнених зір ГП і компіляції для зірок ГП від Mamajek (2018). В результаті ми отримали залежності, які поєднують $T_{\text {eff }}, \log$ g, радіуси, маси та відстані для справжніх членів - зір ГП з Collinder. Ми підтвердили правильність відстаней GAIA DR2 (2018) для цих зірок та визначили їх радіуси та маси. Останні оцінки виявилися близькими до оцінок еволюційних мас, які розраховані за моделями PARSEC.

Key words: Open clusters: distanses ; Stars: GAIA distances, $T_{\text {eff }}, \log$ g, radii, masses; main sequence stars; individual: Collinder 394, HD 174723, HD 174706, HD 174685, HD 174651, HD 174652, CPD $-20^{\circ} 5300, \mathrm{CPD}-20^{\circ} 7248, \mathrm{CPD}-20^{\circ} 7240, \mathrm{HD}$ 174594, HD 174307. 


\section{Introduction}

In our previous work (Usenko et al., 2019) we carried out a detailed spectroscopic study of stars from the Turner \& Prederos (1985) list that are related to the Collinder 394 open cluster membership. We have established which of the objects from our observational list are confident members of the cluster and which are foreground and background stars. The atmospheric parameters of these stars obtained by us in combination with their distances determined from the GAIA DR2 (2018) parallaxes allowed us to determine the luminosities, radii and, separately, the masses for objects located on the open cluster's main sequence. These data can help to monitor the evolutionary properties of Collinder 394. Moreover, the use of these data for open clusters that contain Cepheids together with their ages could help to determine the Cepheids "period - age" relationship (Medina et al., 2021).

On the other hand, the evident differences between the published distance values: $643 \pm 25$ pc (Turner \& Prederos, 1985), 703 pc (Kharchenko et al., 2005), 668 pc (Dib et al., 2018), and $657.7 \pm 66.7$ pc (Usenko et al., 2019) raised the question about reliability of the GAIA DR2 (2018) distances. As seen in Table 3 of Usenko et al. (2019), the absolute magnitudes of cluster's main-sequence (MS) stars determined from photometry and from GAIA DR2 (2018) parallaxes show significant differences. Thus we need to check whether the distances to these stars published in the GAIA DR2 (2018) catalogue are correct.

\section{Target setting}

As known, open clusters' MS stars in the HR diagram form a relationship between their $T_{\text {eff }}$ and absolute magnitudes. Since these parameters are connected with luminosities and radii directly, we can say that there is a dependence of these radii on temperatures. Open clusters' MS stars make up strips of different width. In the case of Collinder 394 the strip is narrow (Medina et al., 2021). Hence, having $T_{\text {eff }}$ and distances for the Collinder 394 confident MS stars we can determine their radii. After that we can compare these radii estimates with the ones from the MS calibrations. Therefore the question arises: which calibration to use? In this case we have preferred to use the data from Torres et al. (2010) and Mamajek (2018).

\subsection{Torres et al. (2010), hereafter TAL10}

These authors have analyzed 95 detached noninteracting eclipsing systems with III - V luminosity class stars near the Solar system to obtain their accurate masses, radii, $T_{\text {eff }}$, surface gravities, and projectional rotational velocities. We can use these data to build the calibration base to compare their radii esti-

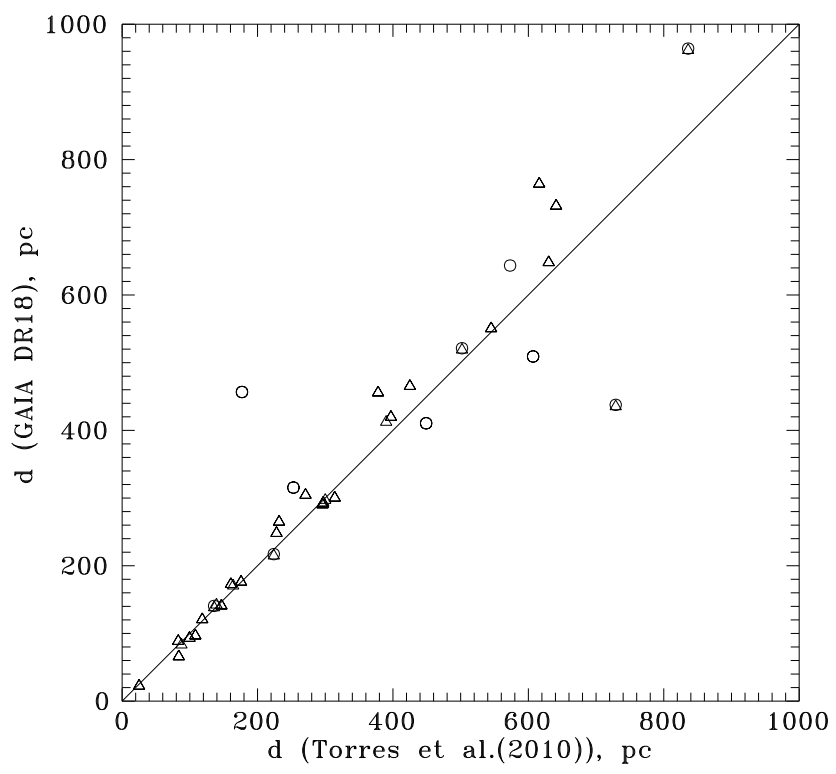

Figure 1: Relationship between the distance values for MS stars from TAL10) list and corresponded GAIA DR2 (2018) ones. Open circles show the objects with $\log \mathrm{g}=3.5-3.9$, triangles show those with $\log \mathrm{g}=3.9-$ 4.5 .

mates with the same determined from the GAIA DR2 (2018) distances and our $T_{\text {eff }}$ and $\log$ gfor the Collinder 394 confident MS stars. We have selected a total of 70 stars from the Torrres et al. (2010) list in a $T_{\text {eff }}$ range from $17000 \mathrm{~K}$ to $7000 \mathrm{~K}(\mathrm{~B} 4 \mathrm{~V}-\mathrm{F} 0 \mathrm{~V})$ and $\log$ gfrom 3.50 to 4.50 . Figure 1 shows a relationship between the distances for these stars and corresponding GAIA DR2 (2018) distances. The best agreement between these values is observed for distances up to $300 \mathrm{pc}$. However, a few stars with log gbetween 3.5 to 3.9 show significant deviation.

\subsection{Mamajek (2018), hereafter MAM18}

MAM18 presents the compilation of the MS stars color-indices, $T_{\text {eff }}$, bolometric corrections, absolute magnitudes, masses, radii, and ages in a range from $46000 \mathrm{~K}$ to $250 \mathrm{~K}$. For our calibration we used the data from B3 $\mathrm{V}$ to $\mathrm{F} 1 \mathrm{~V}$ type with an increment of one spectral unity.

\section{Calibrations and results}

\subsection{Radii}

We found a " $T_{\text {eff }}-$ radius" relationship based on the selected data from TAL10. At first, we divided the data from Table 2 of this paper into two groups: with $\log \mathrm{g}=3.5-3.9$ and with $\log \mathrm{g}=3.9-4.5$. As seen in Fig. 2, only the second group form a cluster that can be approximated by a linear relation, such as:

$$
R / R_{\odot}=1.066+0.00011 \times T_{\text {eff }}
$$




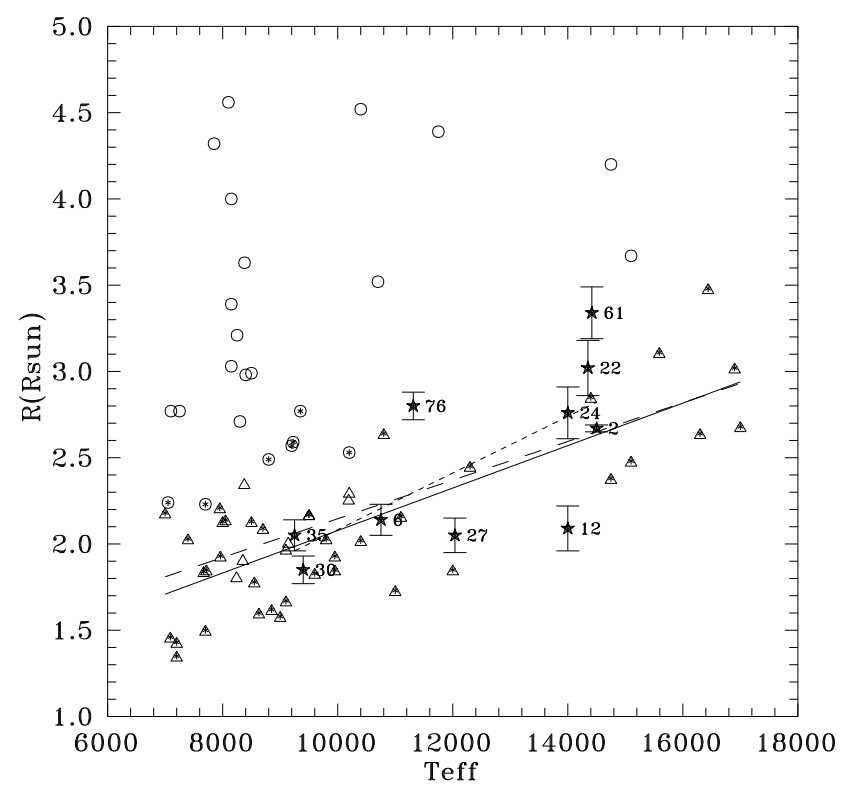

Figure 2: Relationships between the $T_{\text {eff }}$ and radius for the MS stars from TAL10 list and the confident MS stars from Collinder 394. Open circles show the objects with $\log g=3.5-3.9$, triangles $-3.9-4.5$, sixpointed stars - with $\log g=3.9-4.5$ selected to be close to the GAIA DR2 (2018) distances, filled five-pointed stars - confident Collinder $394 \mathrm{MS}$ stars. The solid line shows the relationship described by Eq. 1, the dashed line shows the relationship for the confident Collinder 394 MS stars.

For the purity of the experiment, in Fig. 2 we marked those stars from the second group whose distances given in this paper do not differ much (within $30 \mathrm{pc}$ ) from those given in the GAIA DR2 (2018) catalogue. As seen in Fig. 2, there is no significant difference that affect the above linear dependence. Then we placed our data for the Collinder 394 confident MS stars, there their radii were determined from our

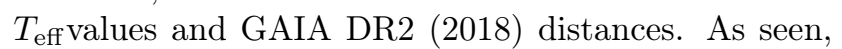
the linear approximation is close to the above:

$$
R / R_{\odot}=0.441+0.000164 \times T_{\text {eff }}
$$

It can be seen that the data in the first group are very scattered, and it is very difficult to derive a good approximation. Nevertheless, as seen in Fig. 2, the majority of the Collinder 394 confident MS stars are located in the region of the calibration stars with $\log \mathrm{g}=$ $3.9-4.5$, except for stars No.61 and No.76 which have log gof 3.78 and 3.87, respectively. Although, stars No.24 and No.35 have $\log \mathrm{g}=3.62$ and 3.63, they are located close to the linear relationship (1).

Figure 3 shows positions of the Collinder 394 MS stars and a linear relation for the MAM18 calibration data for B3 V-F1 V stars as:

$$
R / R_{\odot}=0.419+0.000182 \times T_{\text {eff }}
$$

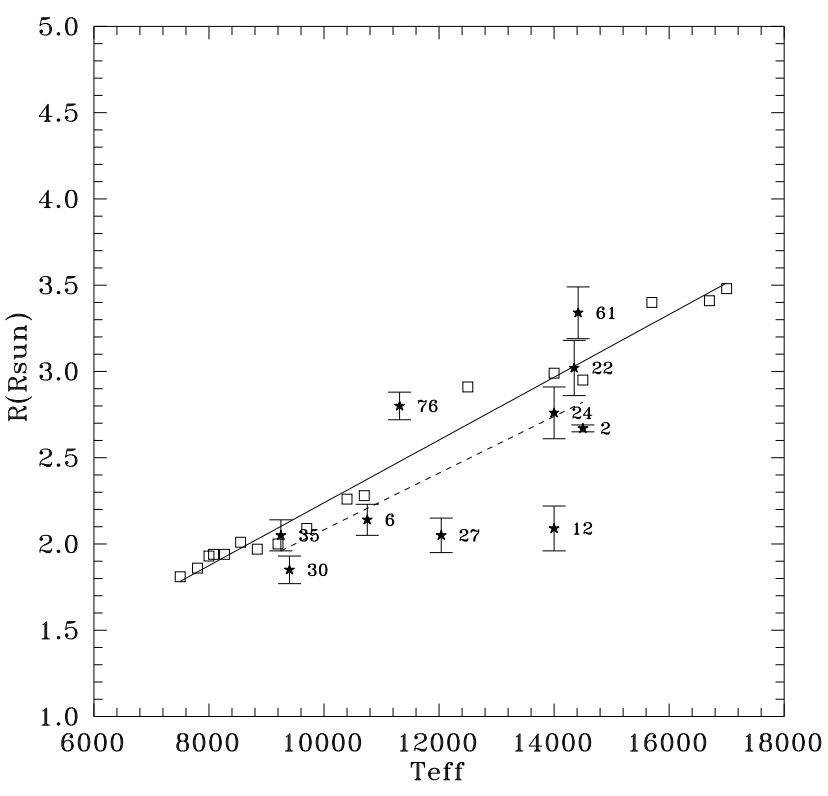

Figure 3: Relationships between $T_{\text {eff }}$ and radius for the MS stars from MAM18 and confident MS stars from Collinder 394. Squares - data from the MAM18 table, filled five-pointed stars - the confident Collinder 394 MS stars. The solid line shows the relationship described by Eq.3, the dashed line shows the relationship for the confident Collinder 394 MS stars.

This relationship differs from that for the confident MS stars from Collinder 394. Table 1 shows the radii of these stars determined by both methods. As seen, the most deviations in the case of TAL10 data demonstrate stars No.61 and No.76, mentioned above, and star No.12 with $\log g=4.30$, all of which exceed $0.5 R_{\odot}$. In the case of MAM18 data we note that the stars No. 12 too and No.27 with $\log \mathrm{g}=4.19$.

\subsection{Masses}

As was mentioned above, eclipsing binaries that consist of MS stars are attractive objects, because their masses and radii can be determined with a high accuracy. Also, these parameters are convenient for form-

Table 1: Comparison between radii determined using the GAIA DR2 (2018) distances and those from the relationships 1 and 3 based on the TAL10 and MAM18 data.

data.
\begin{tabular}{|l|c|c|c|}
\hline Object & $\begin{array}{c}\text { GAIA DR2 } \\
\left(R\left(R_{\odot}\right)\right)\end{array}$ & $\begin{array}{c}\text { TAL10 } \\
\left(R\left(R_{\odot}\right)\right)\end{array}$ & $\begin{array}{c}\text { MAM18 } \\
\left(R\left(R_{\odot}\right)\right)\end{array}$ \\
\hline 2 (HD 174723) & $2.67 \pm 0.02$ & 2.66 & 3.06 \\
6 (HD 174706) & $2.14 \pm 0.09$ & 2.25 & 2.38 \\
12 (HD 174685) & $2.09 \pm 0.13$ & 2.61 & 2.97 \\
22 (HD 174651) & $3.02 \pm 0.16$ & 2.65 & 3.03 \\
24 (HD 174652) & $2.76 \pm 0.15$ & 2.61 & 2.97 \\
27 (CPD -20 5300$)$ & $2.05 \pm 0.10$ & 2.38 & 2.61 \\
30 (CPD -20 7248) & $1.85 \pm 0.08$ & 2.10 & 2.13 \\
35 (CPD -20 7240) & $2.05 \pm 0.09$ & 2.08 & 2.10 \\
61 (HD 174594) & $3.34 \pm 0.15$ & 2.65 & 3.04 \\
76 (HD 174307) & $2.80 \pm 0.08$ & 2.31 & 2.48 \\
\hline
\end{tabular}




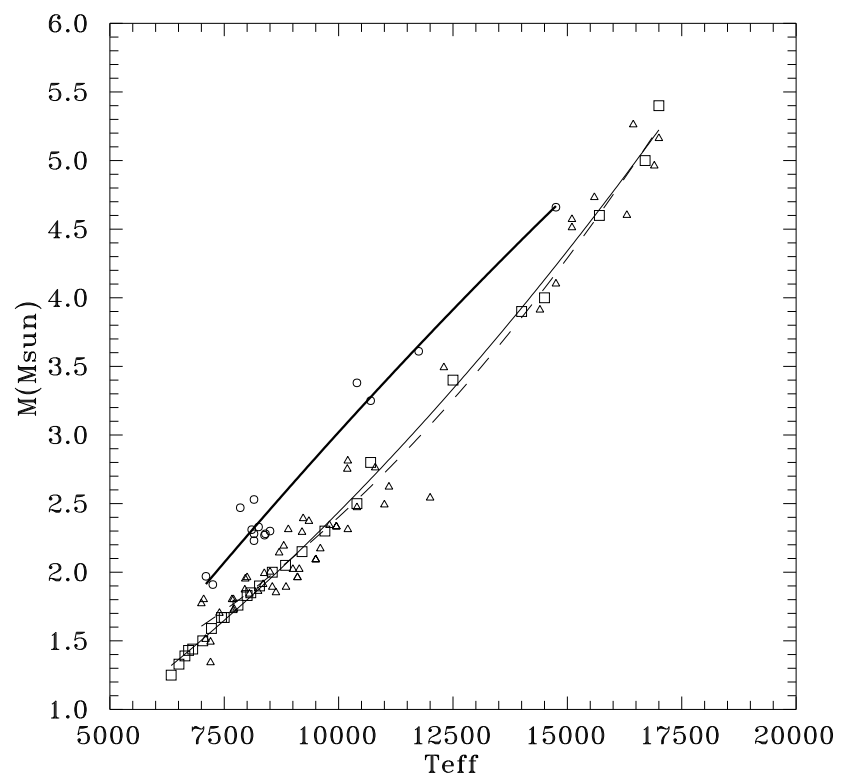

Figure 4: Relationships between $T_{\text {eff }}$ and mass for the MS stars from TAL10 with $\log g=3.5-3.9$ (open circles), $\log \mathrm{g}=3.9-4.5$ (triangles), and those from MAM18 (squares). The thick line shows the first case (Eq. 4), the solid line shows second case (Eq. 5), and the dashed line shows the third case (Eq. 6).

ing the basis for the confident MS open clusters' stars. Therefore, in this section we analyze the " $T_{\text {eff }}-$ mass" and "radius - mass" relationships based on the TAL10 and MAM18 data and determine the masses for the Collinder 394 confident MS stars. Figure 4 shows these relationships between $T_{\text {eff }}$ and masses for MS stars. As seen, their relationships for the objects with $\log \mathrm{g}=3.5$ -3.9 and those with $\log \mathrm{g}=3.9-4.5$ can be approximated by a 2nd degree polynomial:

$$
\begin{aligned}
& M / M_{\odot}=-1.117+4.6 \cdot 10^{-4} \times T_{\text {eff }}-5 \cdot 10^{-9} \times T_{\mathrm{eff}}^{2} \\
& M / M_{\odot}=0.735+2.6 \cdot 10^{-5} \times T_{\mathrm{eff}}+1.4 \cdot 10^{-8} \times T_{\mathrm{eff}}^{2}
\end{aligned}
$$

In the case of the MAM18 data we derived:

$$
M / M_{\odot}=-0.071+1.65 \cdot 10^{-4} \times T_{\mathrm{eff}}+9 \cdot 10^{-9} \times T_{\mathrm{eff}}^{2} .
$$

Relationships (5) and (6) are sufficiently close to one another. Table 2 represents our mass values for the confident Collinder 394 MS stars. There is a good coincidence in the case of $\log \mathrm{g}=3.9-4.5$ and the MAM18 data. But for stars No.24, No.61 and No.76 with observational $\log$ gfrom 3.5 to 3.9 the masses are overestimated.

Figure 5 shows the data similar to those shown in Fig. 4, but for the mass - radius relationships. As seen in Fig. 5, the TAM10 objects with $\log \mathrm{g}=3.5-3.8$ exhibit a wide data scatter. If we use a smaller number of these objects, keeping those whose distances that do not differ more than $30 \mathrm{pc}$ from those given in the

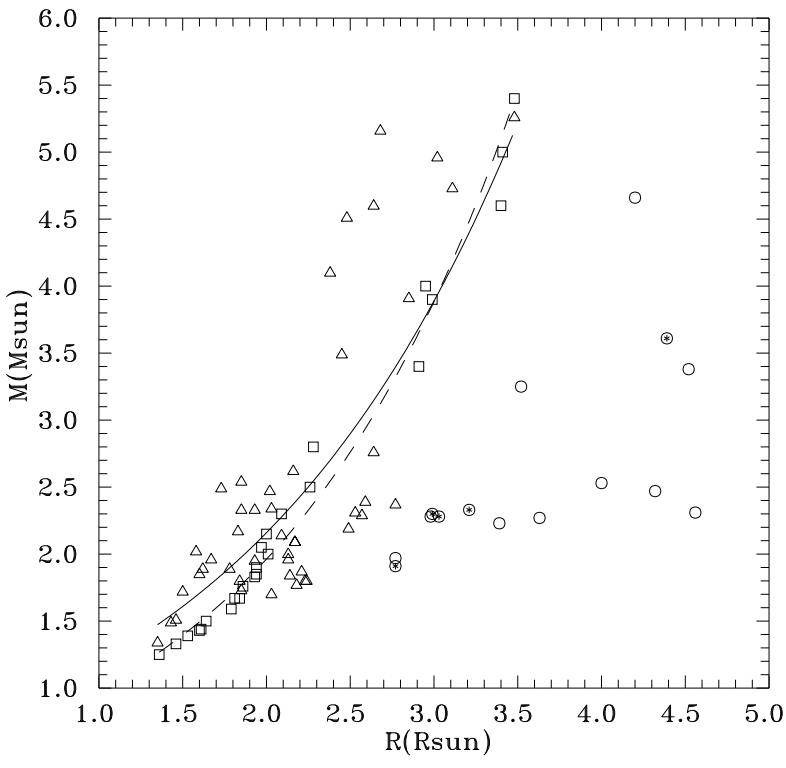

Figure 5: Relationships between the radii and masses for MS stars from TAL10 with $\log \mathrm{g}=3.5-3.9$ (open circles and six-pointed stars), $\log g=3.9-4.5$ (triangles), and MAM18 (squares). The solid line shows second case (Eq. 7), and the dashed line shows the third case (Eq. 8).

GAIA DR2 (2018) catalogue (such as in Sect. 3.1, sixpointed stars), only five stars remains. On the other hand, data for the TAL10 objects with $\log \mathrm{g}=3.9-4.5$ and for the MAM18 objects can be approximated by exponential relationships, respectively:

$$
M / M_{\odot}=0.67 \exp ^{0.59 R}
$$

and

$$
M / M_{\odot}=0.5 \exp ^{0.68 R}
$$

Table 3 contains the masses for the confident Collinder 394 MS stars obtained from the "mass - ra-

\begin{tabular}{|c|c|c|c|}
\hline \multirow[t]{2}{*}{ Object } & \multicolumn{2}{|c|}{ TAL10 } & MAM18 \\
\hline & $\begin{array}{c}\log g \\
3.5-3.9\end{array}$ & $\begin{array}{c}\log g \\
3.9-4.5\end{array}$ & \\
\hline 2 (HD 174723) & - & 4.06 & 4.21 \\
\hline 6 (HD 174706) & - & 2.63 & 2.74 \\
\hline $12(\mathrm{HD} 174685)$ & - & 3.84 & 4.00 \\
\hline 22 (HD 174651) & - & 3.99 & 4.15 \\
\hline 24 (HD 174652) & 6.29 & 3.84 & 4.00 \\
\hline $27\left(\mathrm{CPD}-20^{\circ} 5300\right)$ & - & 3.08 & 3.22 \\
\hline $30\left(\mathrm{CPD}-20^{\circ} 7248\right)$ & - & 2.22 & 2.28 \\
\hline $35\left(\mathrm{CPD}-20^{\circ} 7240\right)$ & - & 2.17 & 2.23 \\
\hline $61(\mathrm{HD} 174594)$ & 6.54 & 4.02 & 4.18 \\
\hline 76 (HD 174307) & 4.72 & 2.82 & 2.95 \\
\hline
\end{tabular}
dius" relationships. As seen, differences in the masses

Table 2: Comparison between the confident Collinder $394 \mathrm{MS}$ stars masses determined using our $T_{\text {eff }}$ and relationships based on the TAL10 and MAM18 data. 


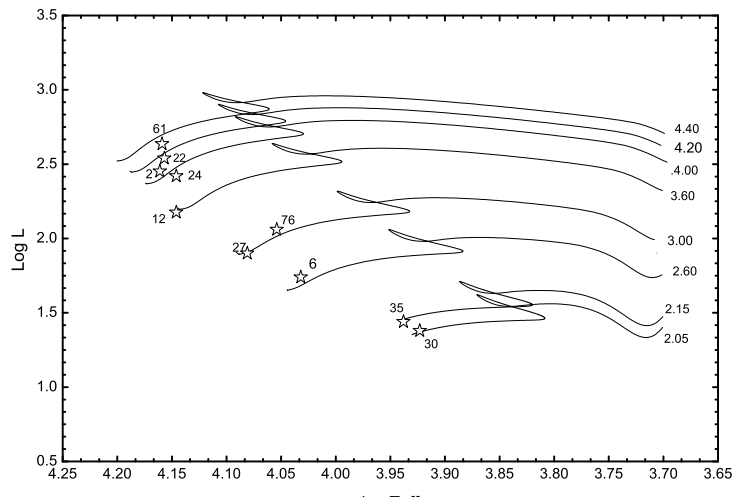

Figure 6: Evolutionary tracks from the PARSEC (Bressan et al., 2018) code calculated for the MS stars and positions of the confident Collinder 394 MS stars on the HR diagram.

between GAIA DR2 (2018) and the TAL10 radius estimates do not exceed $0.5 M_{\odot}$ except for stars No.12, No.22, No.61 and No.76. In the case of the MAM18 radii, the same difference is visible for star No.2 as well. As a whole, the MAM18 estimates from Table 3 are the closest to those from Table 2 .

Figure 6 represents the evolutionary tracks of MS stars with masses from 2.05 to $4.40 \mathrm{M}_{\odot}$ calculated using the PARSEC code (Bressan et al. 2012). There is a good agreement between the calculated evolutionary masses and our estimates, determined by using the " $T_{\text {eff }}-$ mass" and "radius - mass" relationships based on the TAL10 and MAM18 calibrations.

\section{Summary}

1. We have used calibrations for MS stars based on the parameters found for the nearest eclipsing binaries (TAL10) or compilations of these parameters (MAM18) to derive the radii and masses of the confident Collinder 394 MS stars and to check the accuracy of the GAIA DR2 (2018) distances.

2. Calibrations found with the TAL10 base are sensitive to the surface gravity values. The best match in the distance values for the calibration stars between TAL10 and GAIA DR2 (2018) occurs in case of $\log \mathrm{g}=3.9-4.5$, while objects with $\log \mathrm{g}=$ $3.5-3.9$ demonstrate significant deviations.

3. The " $T_{\text {eff- }}$ radius" relationship based on the TAL10 objects has a better linear approximation for the calibration stars with $\log g=3.9-4.5$. A similar relationship was found for the confident Collinder 394 MS stars and turned out to be close to the previous one. The same relationship based on the MAM18 calibration gives a slight difference for these objects. Therefore the radii of these cluster stars determined from the GAIA DR2 (2018)
Table 3: Comparison between the confident Collinder 394 MS stars masses determined using the radii from Table 1 and relationships based on the TAL10 and MAM18 data.

\begin{tabular}{|c|c|c|c|c|}
\hline Object & \multicolumn{2}{|c|}{ GAIA DR2 } & TAL10 & MAM18 \\
\hline & TAL10 & MAM18 & & \\
\hline 2 (HD 174723) & $3.24 \pm 0.03$ & $3.07 \pm 0.03$ & 3.22 & 4.01 \\
\hline $6(\mathrm{HD} 174706)$ & $2.37 \pm 0.12$ & $2.17 \pm 0.13$ & 2.53 & 2.53 \\
\hline 12 (HD 174685) & $2.30 \pm 0.17$ & $2.07 \pm 0.20$ & 3.13 & 3.77 \\
\hline 22 (HD 174651) & $3.98 \pm 0.35$ & $3.90 \pm 0.45$ & 3.20 & 3.92 \\
\hline $24(\mathrm{HD} 174652)$ & $3.41 \pm 0.28$ & $\begin{array}{l}3.90 \pm 0.45 \\
3.27 \pm 0.35\end{array}$ & $\begin{array}{l}3.20 \\
3.13\end{array}$ & $\begin{array}{l}3.92 \\
3.77\end{array}$ \\
\hline $27\left(\mathrm{CPD}-20^{\circ} 5300\right)$ & $2.25 \pm 0.13$ & $2.02 \pm 0.14$ & 2.73 & 2.95 \\
\hline $30\left(\mathrm{CPD}-20^{\circ} 7248\right)$ & $2.00 \pm 0.09$ & $1.76 \pm 0.10$ & 2.31 & 2.13 \\
\hline $35\left(\mathrm{CPD}-20^{\circ} 7240\right)$ & $2.25 \pm 0.11$ & $2.02 \pm 0.12$ & 2.29 & 2.09 \\
\hline $61($ HD 174594) & $4.81 \pm 0.38$ & $4.85 \pm 0.52$ & 3.20 & 3.95 \\
\hline 76 (HD 174307) & $3.50 \pm 0.15$ & $3.36 \pm 0.18$ & 2.62 & 2.70 \\
\hline
\end{tabular}

distances are close to those determined from the TAL10 calibration for $\log g=3.9-4.5$. For three stars within $\log \mathrm{g}=3.5-3.9$ the radii are close to the ones determined from the MAM18 calibration.

4. Masses of the confident Collinder 394 MS stars using " $T_{\text {eff- }}$ mass" relationships are close to both TAL10 and MAM18 calibrations as well as to the evolutionary masses calculated using the Bressan et al. (2012) PARSEC models. In the case of the "radius - mass" relationships, these values are close to the evolutionary masses based on the MAM18 calibration. In general, if we compare the mass estimates obtained from the " $T_{\text {eff }}-$ mass" and "radius - mass" relationships, then the former one is better based on the TAL10 calibration, while the latter is better based on the MAM18 one.

5. The distances for the confident Collinder $394 \mathrm{MS}$ stars using the GAIA DR2 (2018) ones were found to be reliable.

\section{References}

Bressan A., Marigo P., Girardi L., Salasnich B., Dal Cero C., Rubele S., Nanni A.: 2012, MNRAS, 427, 127. Dib S., Schmeja S., Parker R.J.: 2018, MNRAS, 473, 894. GAIA DR2: 2018, CDS/ADS Collection of Electronic Catalogues, 1345.

Kharchenko N.V., Piskunov A.E., Röser S., Schilbach E., Scholz R.-D.: 2005, A\&A, 438, 1163.

Mamajek E.: 2018, "A Modern Mean Dwarf Stellar Color And Effective Temperature Sequence", http://www.pas.rochester.edu/ emamajek/EEM_ dwarf_UBVRIJHK_colors_T $T_{\text {eff }}$.txt.

Medina G.E, Lemasle B., Gerbel E.K.: 2021, MNRAS, 505, 1342.

Torres G., Andersen J., Giménes A.: 2010, A $6 A R v, 18,67$. Turner D.G.\& Prederos M.: 1985, AJ, 90, 1231.

Usenko I.A., Kniazev A.Yu., Katkov I.Yu., Kovtyukh V.V., Mishenina T.V., Miroshnichenko A.S., Turner D.G.: 2019, Odessa Astron. Publ., 32, 91. 